\title{
Trying to predict the unpredictable: Variations in device-based daily monitored diagnostic parameters can predict malignant arrhythmic events in patients undergoing cardiac resynchronization therapy*
}

Ewa Jędrzejczyk-Patej, Oskar Kowalski, Beata Średniawa, Patrycja Pruszkowska, Adam Sokal, Mariola Szulik, Michał Mazurek, Jacek Kowalczyk, Zbigniew Kalarus, Radosław Lenarczyk; for the Triple-Site Versus Standard Cardiac Resynchronization Trial (TRUST CRT) Investigators

Department of Cardiology, Congenital Heart Disease and Electrotherapy, Silesian Medical University, Silesian Centre for Heart Diseases, Zabrze, Poland

\begin{abstract}
Background: The aim of this study was to evaluate the value of device-based diagnostic parameters in predicting ventricular arrhythmias in cardiac resynchronization therapy (CRT) recipients. Methods: Ninety-six CRT-D patients participating in TRUST CRT Trial were analyzed. The inclusion criteria were: heart failure in NYHA $\geq 3$ class, QRS $\geq 120 \mathrm{~ms}, \mathrm{LVEF} \leq 35 \%$ and significant mechanical dyssynchrony. Patients were divided into those with $(n=31,92$ arrhythmias) and without $(n=65)$ appropriate ICD interventions within follow-up of $12.03 \pm 6.7$ months. Daily monitored device-based parameters: heart rate (HR), thoracic impedance (TI), $H R$ variability and physical activity were analyzed in 4 time windows: within 10, 7, 3 days and 1 day before appropriate ICD interventions.
\end{abstract}

Results: A consistent pattern of changes in three monitored factors was observed prior to arrhythmia: 1) a gradual increase of day HR (from 103.43\% of reference within 10-day window to $105.55 \%$ one day before, all $p<0.05$ vs. reference); 2) variations in night $H R(104.75 \%$ in 3 days, 107.65\% one day before, all $p<0.05$ ) and 3) TI decrease (from 97.8\% in 10 days to $96.81 \%$ one day before, all $p<0.05)$. The combination of three parameters had better predictive value, which improved further after exclusion of patients with atrial fibrillation $(A F)$. The predictive model combining HR and TI together with LVEF and NT-proBNP was more prognostic than the model involving LVEF and NT-proBNP alone (difference in AUC 0.05, 95\% CI 0.0005-0.09, $p=0.04$ ).

Conclusions: Daily device-monitored parameters show significant variations prior to ventricular arrhythmia. Combination of multiple parameters improves arrhythmia predictive performance by its additive value to baseline risk factors, while presence of AF diminishes it. (Cardiol J 2014; 21, 4: 405-412)

Key words: device-based monitoring, cardiac resynchronization therapy, ventricular arrhythmia, intrathoracic impedance, heart rate, heart failure

Address for correspondence: Ewa Jędrzejczyk-Patej, MD, Department of Cardiology, Congenital Heart Disease and Electrotherapy, Silesian Medical University, Silesian Centre for Heart Diseases, ul. Skłodowskiej-Curie 9, 41-800 Zabrze, Poland, tel: +4832 3733 682, fax: +4832 3733 792, e-mail: ewajczyk@op.pl

Received: 13.07.2013

Accepted: 23.02.2014

*Study data were presented at the Congress of the European Society of Cardiology, 31 August 2013 - 04 September 2013, Amsterdam, Netherlands. The trial was registered at ClinicalTrials.gov. Trial Identifier: NCT008148. 


\section{Introduction}

Despite the positive effects of biventricular pacing [1-5], heart failure (HF) patients still remain at increased risk of life-threatening ventricular arrhythmias. Appropriate shocks are associated with increased risk of death [6]. Presently implanted devices are capable of measuring various parameters such as averaged heart rates, heart rate variability (HRV), patient physical activity and intra-thoracic impedance (TI). Some studies indicated that changes in these measures are associated with increased hospitalization rates due to exacerbated $\mathrm{HF}[7,8]$. Little is known about the changes in device-measured parameters that occur prior to malignant arrhythmias, which would make it possible to predict serious arrhythmic events. The aim of this study was to evaluate the prognostic value of daily monitored device-based diagnostic parameters as predictors of malignant ventricular arrhythmias in patients undergoing cardiac resynchronization therapy (CRT).

\section{Methods}

\section{Study population}

Study population consisted of patients included in the Triple-Site Versus Standard Cardiac Resynchronization Therapy Trial (TRUST CRT) which was a prospective, randomized, single center trial to assess the effectiveness of triple-site pacing versus standard resynchronization therapy [9]. The study included HF patients in New York Heart Association (NYHA) class III-IV, with sinus rhythm, QRS width $\geq 120 \mathrm{~ms}$, left ventricular ejection fraction (LVEF) $\leq 35 \%$ and significant ( $\geq 40 \mathrm{~ms}$ ) inter- or intra-ventricular mechanical dyssynchrony.

Patients were randomized in a $1: 1$ ratio to conventional or triple-site (dual-left, single-right) CRT-D. The enrollment began in February 2008 and was accomplished in January 2010, when 100 consecutive patients were enrolled. All patients were implanted with CRT-D devices (InSync III Sentry, Medtronic, Minneapolis, USA) capable of continuous monitoring and storing daily variations of several parameters. Study protocol and procedural outcomes had been published previously $[9,10]$. Two patients, in whom the implantation of CRT-D failed were not analyzed in the study. Two other subjects were excluded after enrollment (lung cancer in one patient, non-compliance in the second one). Data from 96 patients were used for the analysis.
The study was approved by the local bioethical committee and all patients gave their informed consent.

\section{Device settings and reprogramming}

The pacing and antiarrhythmic settings of CRT-D were programmed identically in all patients (DDD mode, lower pacing rate of $50 \mathrm{bpm}$, ventricular tachycardia (VT) zone 150-200 bpm, ventricular fibrillation (VF) zone $>200 \mathrm{bpm})$. Paced and sensed atrio-ventricular and inter-ventricular delays were optimized echocardiographically 1-3 days after the implantation [9]. All patients were kept on pre-discharge settings of CRT-D during the follow-up and no further routine reprogramming was allowed unless clear indications occurred.

\section{Follow-up, classification of antiarrhythmic interventions and adverse events}

All patients were followed on outpatient basis for 1 week, 1, 3 and 6 months after randomization and every 6 months thereafter. Antiarrhythmic therapies were assessed independently by 2 members of the Arrhythmic Events Assessment Board.

Data on potential adverse events were collected throughout the entire follow-up and adjudicated blindly by 2 experts. Arrhythmia was considered temporarily related to $\mathrm{HF}$ exacerbation if its occurrence was followed by HF hospitalization within next 10 days, or if arrhythmia occurred during hospitalization due to HF exacerbation.

Device-based measurements and collection of data retrieved from pacemakers' memory

At 3-month follow-up and every 6 months thereafter, biometric data collected continuously by devices were downloaded, converted into electronic format (Microsoft Excel, Microsoft, USA) and analyzed. These data included: heart rate during daytime (DHR) and night-time (NHR), daily physical activity, TI and HRV.

CRT devices calculated DHR and NHR as daytime and night-time averages of inter-atrial interval lengths. Patient's daily activity was recognized by the device's sensor and was a daily average of minutes when the patient was active. Daily TI was an average of 64 impedance measurements taken while pacing between right ventricular coil and can. HRV was assessed by device using the median atrial HR determined every $5 \mathrm{~min}$ and variability value (SD of 5 -min median atrial) was plotted each day. 


\section{Analysis of device-stored temporal trends}

At first, 2 reference values of every analyzed parameter were computed for each patient ("baseline" levels of each variable). The first: short-term reference was the mean value of an appropriate parameter between implantation and the first arrhythmia. Considering the possibility, that the first arrhythmia (or implantable cardioverter-defibrillator [ICD] intervention) can change analyzed parameters during further observation, the second: long-term reference was calculated as mean within the whole observation period.

Subsequently, the mean values of HRVs, DHRs, NHRs and TIs were averaged within 4 monitoring windows that preceded directly ICD intervention: within 10-day window (days -10 to -1), 7-day, 3-day and 1-day prior to the first appropriate intervention. In patients with multiple adequate ICD interventions, the mean values of all analyzed parameters were calculated within the same time periods prior to all interventions and then averaged for every patient. If 2 arrhythmias were separated by less than 10 days, the second one was not taken into consideration.

\section{Statistical analysis}

The continuous parameters were presented as mean \pm standard deviation or median \pm range (depending on parameters' distribution), categorical variables as numbers and percentages. Comparison between the groups was performed with $\chi^{2}$, T-Student or Mann-Whitney U tests, as appropriate.

To calculate arrhythmic risk 2 models were analyzed separately and then combined. "Stable risk model" included LVEF and N-terminal proB-type natriuretic peptide (NT-proBNP) values assessed at baseline and after 6 months of CRT. "Dynamic risk model" included all device-monitored parameters, which changed significantly prior to arrhythmia. Daily risk was calculated with "stable" (changing one time in 6 months) and "dynamic" (changing daily) parameters or their combination included as independent variables. The predicted values calculated with logistic regression were considered indicators of daily risk. Their sum was a marker of cumulative risk.

Predictive power of device-based and baseline data was further compared using receiver-operating curves (ROC) characteristics with predicted risk estimates as independent variables. Predictive power of combinations was compared using DeLong method, with pairwise comparisons of the areas under curve (AUC). P value $<0.05$ was considered significant. Statistical analyses were performed using Statistica software package (version 6.0 and 10.0, StatSoft Inc., Tulsa, OK, USA).

\section{Results}

\section{Study population}

During the median follow-up period of $12.03 \pm$ \pm 6.7 months, 439 low-voltage and 68 high-voltage appropriate ICD therapies were launched in $31(32 \%)$ subjects (506 due to VT, 1 due to VF). Out of 507 interventions, $92(18 \%)$ in 31 patients were included into further analysis. The remaining 415 arrhythmias occurred nine or fewer days before ICD intervention in patients with multiple arrhythmic events, thus making it impossible to analyze a 10-day pre-arrhythmic period.

Patients with and without ICD appropriate interventions did not differ with respect to baseline characteristics with the exception of higher baseline NT-proBNP level in subjects who experienced interventions (median 2251 vs. $1271 \mathrm{pg} / \mathrm{mL}$; $\mathrm{p}=0.035)$ (Table 1$)$.

\section{Outcomes and their association with arrhythmia}

All-cause mortality was $4.5 \%$ in patients free of VT/VF, $6.7 \%$ in patients with one arrhythmic event, and $12.5 \%$ in the group with multiple arrhythmias (all $\mathrm{p}=\mathrm{NS})$. Hospitalization rate due to exacerbated $\mathrm{HF}$ was higher in patients with VT/ /VF compared to subjects without any arrhythmia (35.5\% vs. $13.4 \%, \mathrm{p}=0.01$ ), being particularly high in patients who experienced $\geq 2$ arrhythmias (43.7\%, $p=0.005$ vs. arrhythmia-free group). Similarly, the mean number of HF-hospitalizations/patient was higher in patients with than without any ICD intervention ( 0.74 vs. $0.21, p=0.01)$. From among 92 analyzed arrhythmias in 31 patients, only $6(6.5 \%)$ arrhythmias in $4(13 \%)$ patients showed temporal relationship to HF-exacerbation.

\section{Changes in device-based diagnostic parameters prior to arrhythmia and their sensitivity and specificity}

Considering long-term reference as a comparator, there was a gradual increase of DHR up to $103.43 \%$ of reference value within 10 -day monitoring window before the first arrhythmia (days -10 to -1 ), reaching $103.6 \%$ within 7 -day window, $104.6 \%$ within 3 -days and eventually $105.55 \%$ one day before intervention (all $\mathrm{p}<0.05$ vs. reference). Similar findings were observed in the variations of NHR, however a significant increase was restricted to 3 days before arrhythmia. On the contrary, TI 
Table 1. Baseline characteristics of patients with and without appropriate implantable cardioverter-defibrillator (ICD)-intervention.

\begin{tabular}{lccc}
\hline & $\begin{array}{c}\text { Patients with } \\
\text { ICD-interventions (n=31) }\end{array}$ & $\begin{array}{c}\text { Patients without } \\
\text { ICD-interventions (n = 65) }\end{array}$ & $\mathbf{P}$ \\
\hline Age [years] & $62(58-70)$ & $61(56-70)$ & 0.84 \\
Female & $5(16 \%)$ & $16(25 \%)$ & 0.35 \\
NYHA IV & $6(19 \%)$ & $8(12 \%)$ & 0.36 \\
Ischemic etiology & $18(58 \%)$ & $40(61.5 \%)$ & 0.74 \\
QRS [ms] & $172(140-200)$ & $167(156-182)$ & 0.59 \\
Left ventricular ejection fraction [\%] & $23(20-25)$ & $24(21-26)$ & 0.17 \\
NT-proBNP [pg/mL] & $2251(981.7-5251)$ & $1271(694.7-2554)$ & 0.035 \\
Medication at discharge [\%]: & $30(97 \%)$ & & \\
Beta-blocker & $30(97 \%)$ & $65(100 \%)$ & 0.15 \\
ACEl/ARB & $29(94 \%)$ & $63(100 \%)$ & 0.15 \\
Aldosterone antagonist & $30(97 \%)$ & $59(91 \%)$ & 0.44 \\
Loop diuretic & $4(13 \%)$ & $5(8 \%)$ & 0.29 \\
Digoxin & $2(6.5 \%)$ & $4(6 \%)$ & 0.41 \\
Amiodarone & & 0.96 \\
\hline
\end{tabular}

Continuous variables are presented as median (range); ACEI/ARB - angiotensin-converting enzyme inhibitor/angiotensin-receptor blocker, NT-proBNP - N-terminal-proB-type natriuretic peptide, NYHA - New York Heart Association functional class

decreasing significantly, starting 10 days before arrhythmia (97.8\% of reference), reaching $97.7 \%$ within 7 -day window, $97.34 \%$ within 3 days and finally $96.81 \%$ of reference value 1 day before intervention (all $\mathrm{p}<0.05$ ). Daily physical activity and HRV did not demonstrate significant variances preceding ventricular arrhythmias.

In patients with multiple arrhythmias only increase in DHRs and NHRs heralded future ICD intervention, but both parameters were short-term forecasters (significant increase 1 and 3 days prior to intervention).

Taking short-term reference as baseline, DHR and NHR were increasing significantly 3 days before arrhythmia. TI was higher than average within 10- and 7-day monitoring windows, to decline afterwards and reach reference value 3 days prior to arrhythmia (Fig. 1, Table 2).

Changes in device-monitored parameters showed only moderate sensitivity, but high specificity in predicting day-to-day probability of VT/VF (Table 3). The most sensitive parameter was increase in DHR, the most specific parameter was increased HR one night prior to arrhythmia.

Combining 2 most sensitive and most specific parameters resulted in increasing the sensitivity but decreasing the specificity of such combinations. Combination of 3 criteria had the highest specificity (86.1\%), without compromising sensitivity (42.3\%).

After exclusion of patients with at least one episode of atrial fibrillation (AF) recorded by device
(55 patients, $71 \%$ of subjects with VT/VF and $49 \%$ of arrhythmia-free group), the sensitivity of NHR in predicting VT/VF increased to $58 \%$ within 3-day window and to $53 \%$ one day before.

\section{Additive role of device-based diagnostics in long-term and short-term arrhythmia prediction}

Calculating the risk only on the basis of repeated measurements of LVEF and NT-proBNP levels ("stable risk model"), during 38.607 patient-days, median cumulative risk of experiencing arrhythmia was $38.9 \%$ (range 7-261\%) in patients without arrhythmic event and $90.4 \%$ (14-277\%) in patients who experienced appropriate intervention $(\mathrm{p}<0.001)$.

Model involving only daily-changing, devicerecorded parameters as covariates ("dynamic risk model" - threshold crossed for NHR 1-day before arrhythmia or for impedance within 7-day window or for DHR within 3-day window) was less efficient in predicting long-term risk. This model overestimated cumulative probability of appropriate ICD intervention in arrhythmia-free group (64.5\%, range 14-197; $\mathrm{p}=0.003$ vs. stable risk model), whereas risk estimation in the arrhythmic group was similar $(82.2 \%, 27-156, \mathrm{p}=\mathrm{NS}$ vs. stable risk model).

Combination of "stable risk" and "dynamic risk" models into one showed better long-term risk prediction in arrhythmia-free group (37.8\%, range $6-256 ; p=0.03$ vs. baseline risk model and 

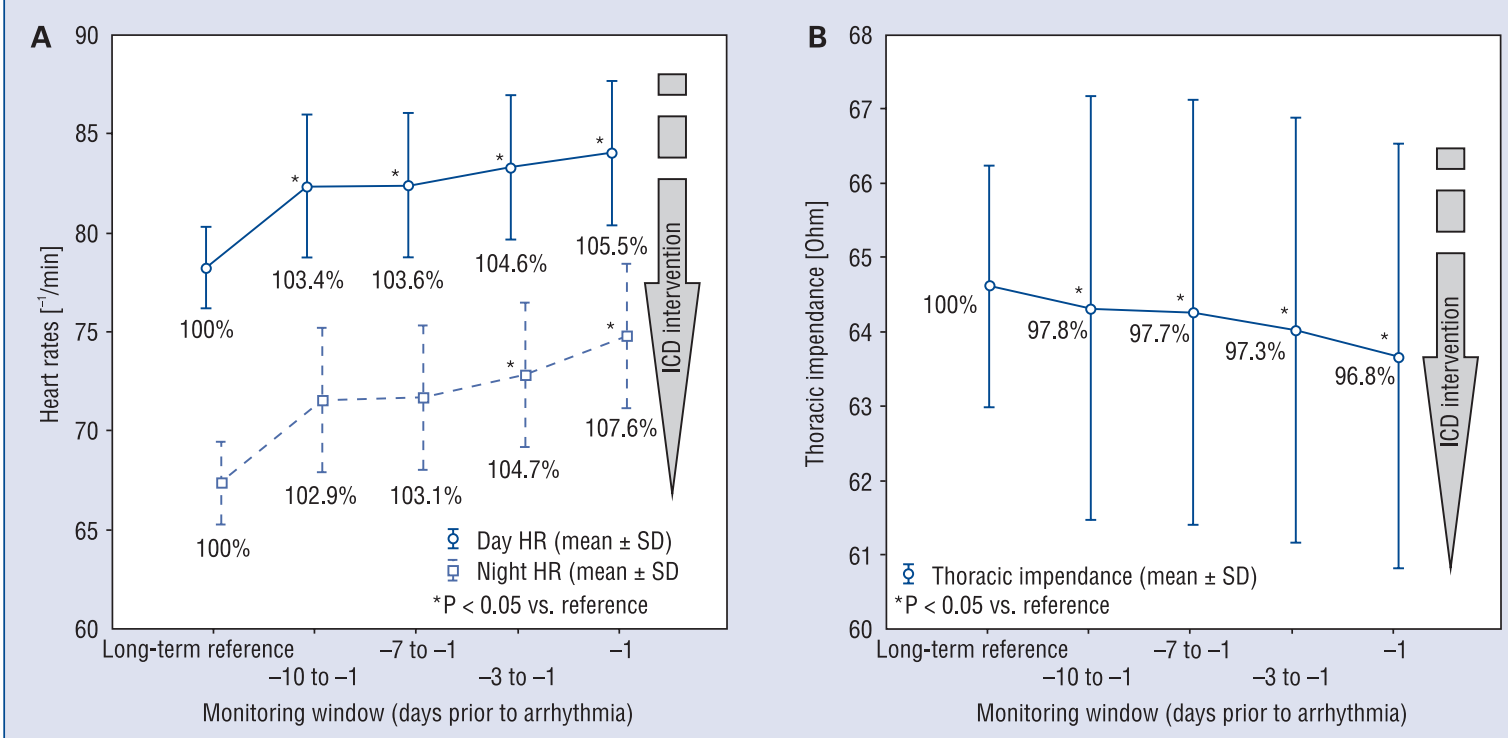

Figure 1. Heart rates (HR) (A) and thoracic impedance (B) prior to the first arrhythmia. Long-term reference - mean value within the whole observation period; ICD — implantable cardioverter-defibrillator.

Table 2. The variability of parameters prior to arrhythmic event.

\begin{tabular}{|c|c|c|c|c|c|c|c|c|c|c|c|}
\hline & \multicolumn{6}{|c|}{$\begin{array}{l}\text { Prior to first ICD-intervention } \\
\text { (31 arrhythmias/31 patients) }\end{array}$} & \multicolumn{5}{|c|}{$\begin{array}{l}\text { Prior to all ICD-intervention } \\
\text { (77 arrhythmias/16 patients) }\end{array}$} \\
\hline & \multirow{2}{*}{$\begin{array}{l}\text { Long- } \\
\text {-term } \\
\text { reference }\end{array}$} & \multirow{2}{*}{$\begin{array}{l}\text { Short- } \\
\text {-term } \\
\text { reference }\end{array}$} & \multicolumn{4}{|c|}{ Days before arrhythmia } & \multirow{2}{*}{$\begin{array}{l}\text { Long- } \\
\text {-term } \\
\text { reference }\end{array}$} & \multicolumn{4}{|c|}{ Days before arrhythmia } \\
\hline & & & $\begin{array}{l}-10 \\
\text { to }-1\end{array}$ & $\begin{array}{c}-7 \\
\text { to }-1\end{array}$ & $\begin{array}{l}-3 \\
\text { to }-1\end{array}$ & -1 & & $\begin{array}{l}-10 \\
\text { to }-1\end{array}$ & $\begin{array}{c}-7 \\
\text { to }-1\end{array}$ & $\begin{array}{c}-3 \\
\text { to }-1\end{array}$ & -1 \\
\hline $\begin{array}{l}\text { Day HR } \\
\text { [bpm] }\end{array}$ & $\begin{array}{c}79.6 \pm \\
6.9\end{array}$ & $\begin{array}{c}80.4 \pm \\
9.1\end{array}$ & $\begin{array}{c}82.4 \pm \\
10.9^{*}\end{array}$ & $\begin{array}{c}82.5 \pm \\
11.2^{*}\end{array}$ & $\begin{array}{l}83.3 \pm \\
11.2^{* \#}\end{array}$ & $\begin{array}{l}84.1 \pm \\
11.8^{* \#}\end{array}$ & $\begin{array}{c}78.2 \pm \\
7.6\end{array}$ & $\begin{array}{c}81.3 \pm \\
11.7\end{array}$ & $\begin{array}{c}81.6 \pm \\
11.8\end{array}$ & $\begin{array}{c}82.7 \pm \\
12.6\end{array}$ & $\begin{array}{c}83.6 \pm \\
12.5^{*}\end{array}$ \\
\hline $\begin{array}{l}\text { Night HR } \\
\text { [bpm] }\end{array}$ & $\begin{array}{c}69.5 \pm \\
7.7\end{array}$ & $\begin{array}{c}70.4 \pm \\
9.6\end{array}$ & $\begin{array}{c}71.6 \pm \\
10.8\end{array}$ & $\begin{array}{c}71.7 \pm \\
10.9\end{array}$ & $\begin{array}{l}72.8 \pm \\
11.9^{* \#}\end{array}$ & $\begin{array}{l}74.8 \pm \\
14.7^{* \#}\end{array}$ & $\begin{array}{c}70.3 \pm \\
7.6\end{array}$ & $\begin{array}{c}73.8 \pm \\
11.5\end{array}$ & $\begin{array}{c}73.9 \pm \\
11.3\end{array}$ & $\begin{array}{c}75.2 \pm \\
12.3^{*}\end{array}$ & $\begin{array}{l}76.9 \pm \\
13.62^{*}\end{array}$ \\
\hline $\begin{array}{l}\text { Activity } \\
\text { [min] }\end{array}$ & $\begin{array}{c}213.3 \pm \\
105\end{array}$ & $\begin{array}{c}208.1 \pm \\
106.9\end{array}$ & $\begin{array}{c}225.8 \pm \\
120.9\end{array}$ & $\begin{array}{c}227.8 \pm \\
130\end{array}$ & $\begin{array}{c}221.8 \pm \\
135.8\end{array}$ & $\begin{array}{c}215.9 \pm \\
142.6\end{array}$ & $\begin{array}{c}179.2 \pm \\
80.8\end{array}$ & $\begin{array}{c}170.7 \pm \\
83.6\end{array}$ & $\begin{array}{c}171.7 \pm \\
84.1\end{array}$ & $\begin{array}{c}173.9 \pm \\
99.1\end{array}$ & $\begin{array}{c}175.3 \pm \\
106.6\end{array}$ \\
\hline $\begin{array}{l}\mathrm{HRV} \\
{[\mathrm{ms}]}\end{array}$ & $\begin{array}{c}96.9 \pm \\
29.1\end{array}$ & $\begin{array}{c}94.6 \pm \\
26.8\end{array}$ & $\begin{array}{c}96.8 \pm \\
28\end{array}$ & $\begin{array}{c}96.6 \pm \\
28.5\end{array}$ & $\begin{array}{c}96.3 \pm \\
28.9\end{array}$ & $\begin{array}{c}95.6 \pm \\
30.9\end{array}$ & $\begin{array}{c}88.6 \pm \\
22.7\end{array}$ & $\begin{array}{c}86.5 \pm \\
24.6\end{array}$ & $\begin{array}{c}87.1 \pm \\
24.8\end{array}$ & $\begin{array}{c}86.7 \pm \\
24.8\end{array}$ & $\begin{array}{c}90.9 \pm \\
29.4\end{array}$ \\
\hline $\begin{array}{l}\text { Impedance } \\
\text { [Ohm] }\end{array}$ & $\begin{array}{c}65.8 \pm \\
7.6\end{array}$ & $\begin{array}{c}63 \pm \\
7.5\end{array}$ & $\begin{array}{c}64.3 \pm \\
8.3^{* \#}\end{array}$ & $\begin{array}{l}64.3 \pm \\
8.4^{* \#}\end{array}$ & $\begin{array}{l}64 \pm \\
8.6^{*}\end{array}$ & $\begin{array}{c}63.7 \pm \\
8.7^{*}\end{array}$ & $\begin{array}{c}65.8 \pm \\
8.5\end{array}$ & $\begin{array}{c}64.9 \pm \\
8.6\end{array}$ & $\begin{array}{c}64.9 \pm \\
8.8\end{array}$ & $\begin{array}{c}65.1 \pm \\
8.8\end{array}$ & $\begin{array}{c}65 \pm \\
9.1\end{array}$ \\
\hline
\end{tabular}

${ }^{*} \mathrm{p}<0.05 \mathrm{vs}$. long-term reference (mean value within whole observation); ${ }^{*} \mathrm{p}<0.05 \mathrm{vs}$. short-term reference (mean value from implant to first intervention); T-tests for dependent samples were used; HR - heart rate; HRV — heart rate variability; ICD — implantable cardioverter-defibrillator

$\mathrm{p}<0.001$ vs. dynamic risk model). Cumulative risk in arrhythmic patients assessed by combined model $(83.2 \%, 15.4-253)$ was similar to the risk assessed separately by each of the two components (both $\mathrm{p}=\mathrm{NS}$ ).

The combined model predicted also highly effective risk of arrhythmia day-by-day, appropriately rating $70 \%$ of cases (AUC $0.70,95 \%$ confidence interval $[\mathrm{CI}] 0.63-0.77 ; \mathrm{p}<0.05)$. The combination was moreover better that baseline risk model (AUC difference $0.05,95 \%$ CI $0.0005-0.09 ; \mathrm{p}=0.04)$ and dynamic model alone (AUC difference $0.09,95 \%$ CI 0.03-0.14; $\mathrm{p}=0.003$ ) in predicting daily risk of arrhythmia (Fig. 2).

\section{Discussion}

Our data indicate that some parameters monitored daily by resynchronization pacemakers do change in specific and reproducible manner prior to 
Table 3. Sensitivity and specificity of diagnostic parameters in predicting arrhythmias.

\begin{tabular}{lcc}
\hline Parameter & All patients/patients without AF \\
\cline { 2 - 3 } & Sensitivity & Specificity \\
\hline DHR within 10 -day monitoring window $\geq 103.4 \%$ reference & $35.2 \% / 36.8 \%$ & $75.7 \% / 76.7 \%$ \\
DHR within 7 days $\geq 103.6 \%$ reference & $43.7 \% / 36.8 \%$ & $75.8 \% / 76.9 \%$ \\
DHR within 3 days $\geq 104.6 \%$ reference & $43.7 \% / 42.1 \%$ & $77.8 \% / 79.3 \%$ \\
DHR 1 day before $\geq 105.5 \%$ reference & $42.3 \% / 42.1 \%$ & $77.3 \% / 78.7 \%$ \\
Impedance within 10 days $\leq 97.8 \%$ reference & $35.2 \% / 26.3 \%$ & $75.5 \% / 77.3 \%$ \\
Impedance within 7 days $\leq 97.7 \%$ reference & $40.8 \% / 36.8 \%$ & $75.0 \% / 76.8 \%$ \\
Impedance within 3 days $\leq 97.3 \%$ reference & $36.6 \% / 31.6 \%$ & $74.7 \% / 76.1 \%$ \\
Impedance 1 day before $\leq 96.8 \%$ reference & $28.2 \% / 21.1 \%$ & $75.0 \% / 76.0 \%$ \\
NHR within 3 days $\geq 104.7 \%$ reference & $42.3 \% / 57.9 \%$ & $79.6 \% / 80.0 \%$ \\
NHR 1 day before $\geq 107.6 \%$ reference & $39.4 \% / 52.6 \%$ & $83.7 \% / 83.6 \%$ \\
NHR 1 day or 7 days heart rate threshold crossed & $54.5 \% / 63.2 \%$ & $68.6 \% / 69.5 \%$ \\
DHR 7 days or 7 days impedance threshold crossed & $64.8 \% / 63.2 \%$ & $56.6 \% / 58.5 \%$ \\
NHR 1 day or impedance 7 days or & $42.3 \% / 52.6 \%$ & $86.1 \% / 86.9 \%$ \\
DHR 3 days threshold crossed (2 of 3 criteria) & & \\
\hline
\end{tabular}

$\mathrm{AF}$ - atrial fibrillation; DHR — day heart rate; NHR — night heart rate

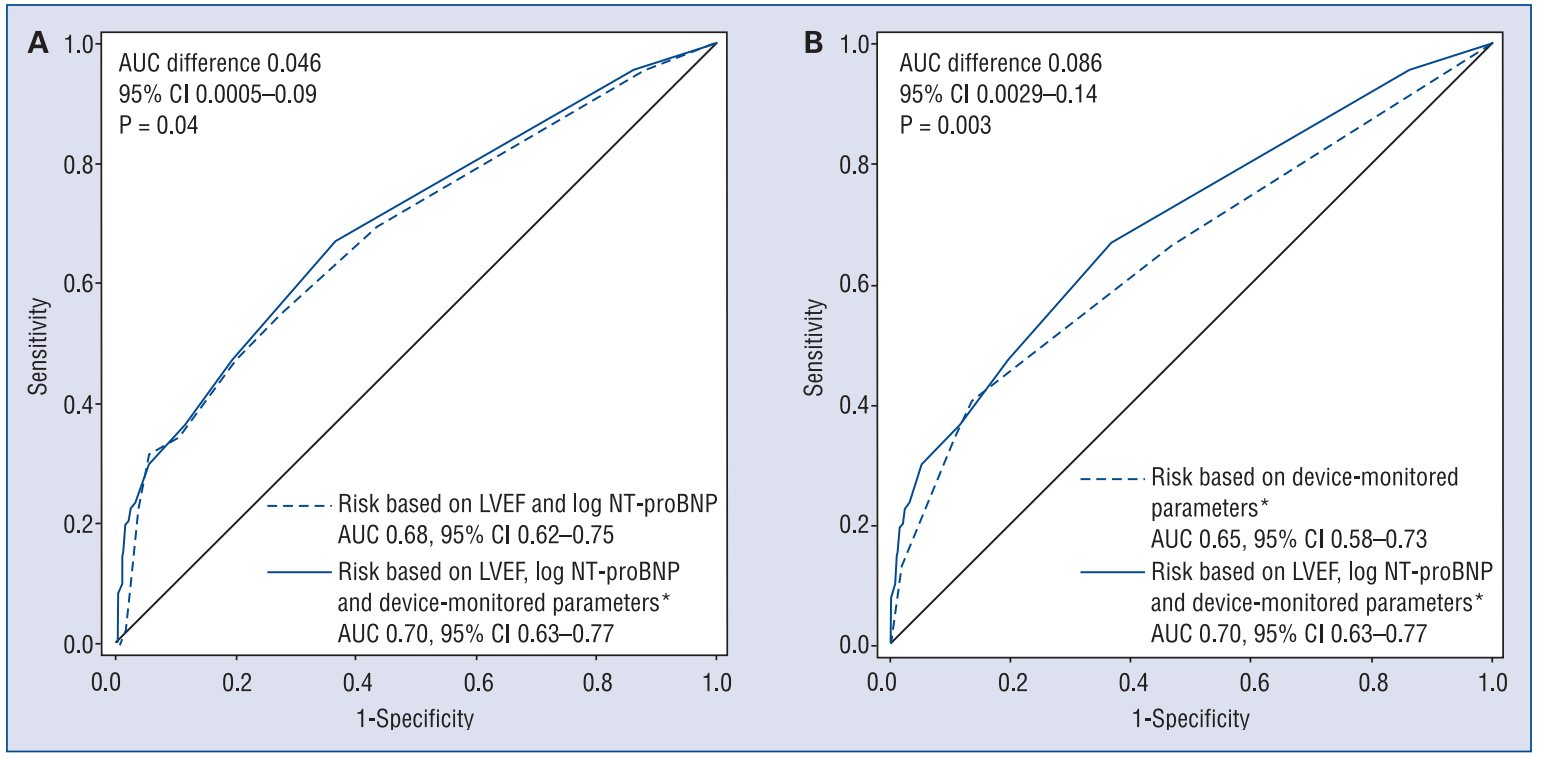

Figure 2. Receiver-operating curves comparing short-term prognostic performance of various predictive models and their combinations; A. Comparison of predictive model based on the left ventricular ejection fraction (LVEF) and log $\mathrm{N}$-terminal proB-type natriuretic peptide (NT-proBNP) alone to the model with additionally included daily recorded device-based parameters; B. Comparison of predictive model based on device-monitored parameters alone to the model with additionally included LVEF and log NT-proBNP; *Device-monitored parameters — predicted values calculated by logistic regression model were used for day-by-day risk assessment. The model was constructed with arrhythmia occurrence on the particular day as dependent binary variable and the most specific combination of device-monitored parameters as independent covariates. This combination included: threshold crossed for night heart rate (HR) 1-day before arrhythmia or for impedance within 7-day monitoring window or for day HR within 3-day window (1 point for each criterion: 0 to 3 points possible for a particular day); $\mathrm{AUC}$ - area under curve; $\mathrm{Cl}-\mathrm{confi-}$ dence interval. 
ventricular arrhythmias. Variations in these parameters become significant as early as 10 days before arrhythmic event if long-term trends are given as reference. Although daily-monitored parameters show moderate sensitivity, they are highly specific. Moreover, the combination of multiple factors can improve their statistical performance. Our results suggest also an additive predictive value of device-monitored parameters in prognosticating both cumulative as well as day-by-day arrhythmic risk as compared to the model based only on LVEF and NT-proBNP.

Device-monitored parameters have been already analyzed as predictors of $\mathrm{HF}$ decompensation or death. Results of these analyses were discordant - non-randomized studies found device-based diagnostic features useful in predicting adverse events, but in DOT-HF randomized trial number of HF hospitalizations was higher in patients with defibrillators equipped with monitor emitting an alert indicating TI decrease [7, 11-19].

The evidence on the role played by device-tracked data in predicting ventricular arrhythmias is very limited. All available analyses concentrated on a single parameter - TI and indicated, that its decline heralds upcoming arrhythmic event [20-22]. Our observations on daily variations in biologic parameters preceding arrhythmia can be explained by several mechanisms, two of which seem to be the most reasonable: transiently elevated sympathetic drive and subclinical hemodynamic decompensation. Elevation in DHRs and NHRs before VT/VF may be attributed to the transient autonomic imbalance, with progressively more accented sympathetic dominance shortly before arrhythmia [23, 24]. Gradually faster HRs together with progressively declining TI prior to arrhythmia suggest the second mechanism involved in arrhythmogenesis - hemodynamic decompensation [25]. Although in studied group only $6 \%$ of arrhythmias showed temporal relationship to HF exacerbation, subclinical decompensation with volume overload and compensatory elevated HR is a very likely mechanism of arrhythmogenesis [20-22]. A progressively decreasing TI with initial plateau and subsequent fast decline prior to arrhythmia is difficult to explain from physiological point of view. This pattern of fluid overload may suggest excessive diuretic use by patients in initial phase of decompensation, leading to electrolyte imbalance and promoting arrhythmia.

\section{Clinical implications}

Our results suggest that during routine follow-up special attention should be paid to increasing
DHR and NHR as well as decreasing TI, especially if multiple parameters are changing simultaneously in patients with no AF. These markers may be particularly useful in subjects without an overt HF decompensation. Because both HR and TI predict only prognosis within the next 1-7 days, their clinical importance may be of limited value in conventionally followed CRT patient. Nevertheless, those parameters may become a powerful prognostic tool, when combined with device remote-monitoring system. An automated algorithm implemented into devices' software, may generate pro-arrhythmic alerts, warning physicians early enough to enable potentially protective measures. Preventive action would then include immediate ambulatory visit in order to screen for symptoms/signs of HF decompensation, ongoing ischemia, electrolyte imbalance, and other potentially pro-arrhythmic states.

\section{Limitations of the study}

Our study was not powered to assess the predictive value of device-monitored parameters. It was designed to compare two CRT-modes. We excluded the majority of arrhythmias because of their temporal relationship with events that were analyzed. However, all patients with at least one arrhythmia within follow-up were analyzed. Strength of our study lies in its prospective, randomized design, the meticulously collected data on all adverse events and blind adjudication of all major adverse cardiac events and arrhythmias.

\section{Conclusions}

Daily device-monitored parameters show reproducibly significant variations prior to ventricular arrhythmia. Combination of multiple parameters improves their predictive performance, whereas presence of $\mathrm{AF}$ diminishes it. Predictive value of these variables is additive to baseline risk factors.

\section{Acknowledgements}

The authors wish to thank Bartlomiej Szwarc, MEng, and Guido Reijntjens, Technical Service Consultant, Medtronic, for technical assistance.

Conflict of interest: Oskar Kowalski - received consultant fees from Medtronic and Biotronik; Beata Średniawa - received consultant fees from Medtronic; Adam Sokal - received consultant fees from Medtronic and Biotronik; Beata Szulik - received lecturer fee from GE Healthcare; Radosław Lenarczyk - received consultant fees from Medtronic and Biotronik. 


\section{References}

1. Anand IS, Carson P, Galle E et al. Cardiac resynchronization therapy reduces the risk of hospitalizations in patients with advanced heart failure: Results from the Comparison of Medical Therapy, Pacing and Defibrillation in Heart Failure (COMPANION) trial. Circulation, 2009; 119: 969-977.

2. Cleland JG, Daubert JC, Erdmann E et al. Cardiac Resynchronization-Heart Failure (CARE-HF) Study Investigators. The effect of cardiac resynchronization on morbidity and mortality in heart failure. N Engl J Med, 2005; 352: 1539-1549.

3. Linde C, Abraham WT, Gold MR, St John Sutton M, Ghio S, Daubert C; REVERSE (REsynchronization reVErses Remodeling in Systolic left vEntricular dysfunction) Study Group. Randomized trial of cardiac resynchronization in mildly symptomatic heart failure patients and in asymptomatic patients with left ventricular dysfunction and previous heart failure symptoms. J Am Coll Cardiol, 2008; 52: 1834-1843.

4. Moss AJ, Hall WJ, Cannom DS et al. Cardiac-resynchronization therapy for the prevention of heart-failure events. N Engl J Med, 2009; 361: 1329-1338.

5. Tang AS, Wells GA, Talajic M et al. Resynchronization-Defibrillation for Ambulatory Heart Failure Trial Investigators. Cardiac-resynchronization therapy for mild-to-moderate heart failure. N Engl J Med, 2010; 363: 2385-2395.

6. Poole JE, Johnson GW, Hellkamp AS et al. Prognostic importance of defibrillator shocks in patients with heart failure. N Engl J Med, 2008; 359: 1009-1017.

7. Adamson PB, Smith AL, Abraham WT et al. Continuous autonomic assessment in patients with symptomatic heart failure: Prognostic value of heart rate variability measured by an implanted cardiac resynchronization device. Circulation, 2004; 110: 238923-94.

8. Small RS, Wickemeyer W, Germany R et al. Changes in intrathoracic impedance are associated with subsequent risk of hospitalizations for acute decompensated heart failure: Clinical utility of implanted device monitoring without a patient alert. J Card Fail, 2009; 15: 475-481.

9. Lenarczyk R, Kowalski O, Średniawa B et al. Triple-Site Versus Standard Cardiac Resynchronization Therapy Study (TRUST CRT): Clinical Rationale, Design and Implementation. J Cardiovasc Electrophysiol, 2009; 20: 658-662.

10. Lenarczyk R, Kowalski O, Sredniawa B et al. Implantation Feasibility, Procedure-Related Adverse Events and Lead Performance During 1-Year Follow-Up in Patients Undergoing Triple-Site Cardiac Resynchronization Therapy: A Substudy of TRUST CRT Randomized Trial. J Cardiovasc Electrophysiol, 2012; 23: 1228-1236.

11. Whellan DJ, Ousdigian KT, Al-Khatib M et al. Combined heart failure device diagnostics identify patients at higher risk of subsequent heart failure hospitalizations: Results from PARTNERS-HF (Program to Access and Review Trending Information and Evaluate Correlation to Symptoms in Patients With Heart Failure) Study. J Am Coll Cardiol, 2010; 55: 1803-1810.
12. Andriulli J. Device monitoring of intrathoracic impedance: Clinical observations from a patient registry. Am J Cardiol, 2007; 99: 23G-28G.

13. Vollmann D, Nägele $H$, Schauerte $P$ et al. Clinical utility of intrathoracic impedance monitoring to alert patients with an implanted device of deteriorating chronic heart failure. Eur Heart J, 2007; 28: 1835-1840.

14. Ypenburg C, Bax JJ, Van der Wall EE, Schalij MJ, van Erven L. Intrathoracic impedance monitoring to predict decompensated heart failure. Am J Cardiol, 2007; 99: 554-557.

15. Yu CM, Wang L, Chau $\mathrm{E}$ et al. Intrathoracic impedance monitoring in patients with heart failure: Correlation with fluid status and feasibility of early warning preceding hospitalization. Circulation, 2005; 112: 841-848.

16. Abraham WT, Compton S, Haas G et al. Intrathoracic impedance vs. daily weight monitoring for predicting worsening heart failure events: Results of the Fluid Accumulation Status Trial (FAST). Congest Heart Fail, 2011; 17: 51-55.

17. Perego GB, Landolina M, Vergara G et al. Implantable CRT device diagnostics identify patients with increased risk for heart failure hospitalization. J Interv Card Electrophysiol, 2008; 23: 235-242.

18. Fantoni C, Raffa S, Regoli F et al. Cardiac resynchronization therapy improves heart rate profile and heart rate variability of patients with moderate to severe heart failure. J Am Coll Cardiol, 2005; 46: 1875-1882.

19. van Veldhuisen DJ, Braunschweig F, Conraads V et al. Intra-thoracic impedance monitoring, audible patient alerts and outcome in patients with heart failure. Circulation, 2011; 124: 1719-1726.

20. Sekiguchi Y, Tada H, Yoshida K et al. Significant increase in the incidence of ventricular arrhythmic events after an intrathoracic impedance change measured with a cardiac resynchronization therapy defibrillator. Circ J, 2011; 75: 2614-2620.

21. Ip JE, Cheung JW, Park D et al. Temporal associations between thoracic volume overload and malignant ventricular arrhythmias: A study of intrathoracic impedance. J Cardiovasc Electrophysiol, 2011; 22: 293-299.

22. Moore HJ, Peters MN, Franz MR, Karasik PE, Singh SN, Fletcher RD. Intrathoracic impedance preceding ventricular tachyarrhythmia episodes. Pacing Clin Electrophysiol, 2010; 33: 960-966.

23. Filipecki A, Trusz-Gluza M, Szydlo K, Giec L. Value of heart rate variability parameters for prediction of serious arrhythmic events in patients with malignant ventricular arrhythmias. Pacing Clin Electrophysiol, 1996; 19: 1852-1856.

24. Bilchick KC, Fetics B, Djoukeng R et al. Prognostic value of heart rate variability in chronic congestive heart failure (Veterans Affairs' Survival Trial of Antiarrhythmic Therapy in Congestive Heart Failure). Am J Cardiol, 2002; 90: 24-28.

25. Aronson D, Burger AJ. Neurohumoral activation and ventricular arrhythmias in patients with decompensated congestive heart failure: Role of endothelin. Pacing Clin Electrophysiol, 2003; 26: 703-710. 